\title{
Integration of Leprosy Control at the Onset of Mass Campaign in Indonesia
}

\author{
M. V. J. BLANC, M.D., \\ Saint Martin-en-Vercors (Drôme), France
}

In the control of endemic communicable diseases it is recommended to undertake operations in thrce successive stages: I. Attack phase, 2. Consolidation phase, and 3 . Integration phase. These different stages fit with different conditions prevailing in the course of a discase control. The WHO Expert Pancl on leprosy (Second Report, Geneva, I96o) recommended them for the organization of leprosy control and they seem necessary for control in areas or countries with high endemicity of leprosy.

However, it seems that, in some circumstances, there might be some advantages in going through to the third phase directly and setting up integration at the onset. Such an attempt began in Indonesia in $195^{8}$. Reasons and main lines of this experiment are reported here.

\section{JUSTIFICATION OF THE INTEGRATION OF A MASS CAMPAIGN AT THE ONSET}

The first reason is the low endemicity of leprosy in Indonesia. It is estimated at one per mile of the total population. The disease is not distributed regularly: some few villages have a prevalence of 20 per mille and it is three per mille in 'regencies' or regions of approximately 400,000 people known as 'high endemicity' areas. But the general average, shown by the results of case-finding in all areas during six years, is 0.96 per mille of the total population covered.

On the basis of these results it did not seem wise to recommend the organization of a specialized service for fighting leprosy in the whole country. On the contrary there were many economic, administrative and technical advantages for choosing integration at the onset.

From the economic point of view, integration enables a cheaper fulfilment of the programme. Relying on the complete organization of the Public Health, it uses its personnel, its buildings, its equipment and means of transportation. The whole programme is sustained by the general budget of Public Health and is not borne by the Leprosy Service only. This solution made possible a larger leprosy control in Indonesia. Without this it would be necessary to restrict mass survey to small areas provided the budget of a specialized service is sufficient. But, in that case, it would not be a true leprosy control.

From the administrative point of view, integration enables a better use of the existing medical personnel aided by paramedical personnel when given an additional training. It may happen that the personnel used for yaws control, who are numerous and spread all over the country in all sub-districts.(around 30,00o inhabitants), has not very many cases of yaws 
to discover and to treat and, in fact, is not fully used. An additional training for the discovery of leprosy lesions gives them a new interest in their work and allows a better use of this personnel. It is noticeable that personnel in charge of communicable disease control should not be limited to the case-finding or treatment of one disease only. Too much specialization leads to routine and, as a result, reduces the output.

Besides that, there is the advantage of not disturbing the population of an area too many times for medical purposes. A great number of meetings would tire the people and cause a considerable decrease in the presence at medical examinations, paralysing any prophylactic operation. This can be avoided by the detection of several diseases during one examination.

'These reasons are still valid in the case of a higher prevalence than in Indonesia. Every opportunity of medical mass examination should be used for the detection of leprosy cases. Even if the diagnosis is not fixed by the para-medical personnel doing the mass survey, the fact that a list of persons suspected of leprosy is established gives an opportunity by the re-examination of a limited number of people, to detect new cases of leprosy. Many cases would not be detected, early cases especially, without this rough screening of almost the entire population.

This rough screening, in addition, avails itself the advantage of a speedy survey of the population. In leprosy control it is more important to detect quickly a large number of patients and to put them under treatment immediately, even if some cases are missed, than to undertake a meticulous survey at low speed in small areas, leaving large territories without protection. The speed of leprosy control should be greater than the spreading of the disease. A specialized service cannot do it easily and it costs much money; an integrated programme does it easily because it expands all its branches in every part of the country. Even if the integrated programme is less perfect, it is more effective, because faster.

Technically, integration is a good means of fighting the prejudices against leprosy. If the disease is detected and treated at the same time as other discases, it is because it obeys the rules of diagnosis and treatment of other diseasess. It is not a disease apart and leprosy patients must not be considered as people bearing a kind of religious punishment. Moreover, very soon, successful treatments will confirm that it is a disease for which something can be done. And these results will be known all the better and quicker when there is no segregation of patients. Then health education is done at the same time.

In the end, at the moment when the mass campaign ends, there will be no problem of re-introducing leprosy control in the normal work of Public Health and there will not be the difficulty of converting the numerous personnel of a specialized service for a new use.

II. PART OF THE SPECIALIZED INSTITUTE AND PERSONNEL If the execution of rough screening and standard treatment are the work of non-specialized Public Health services, it remains that many more 
difficult tasks and the general co-ordination of the programme need a specialized Institute and specialized personnel.

'The study of the problem of leprosy cannot be left to non-specialized services which would not probably give the special care that it necds. Many peculiarities of the disease should be known for an appreciation of the size of the problem, its importance and seriousness.

Training of personnel cannot be done in any otherplace than a specialized Centre, especially for medical doctors and students. Even if all do not become leprologists, it is still necessary that a small number of them become leprologists for the direction and the care of leprosy control. The training of all should be of a good scientific standard taking cognisance of the new trends and discoveries in the field of leprosy.

Research itself is necessary for a renewal of interest in leprosy among doctors and to improve the techniques of mass campaign: better methods of diagnosis, better treatments, etc.

For all these tasks a I.cprosy Institute has a very important part to play in an integrated leprosy control programme.

It remains necessary to have a specialized Leprosy Centre at the head of the country because it appears impossible to set up an organization of control without it. The preparation of a mass campaign cannot be done by other than specialized personncl, planning must take into account many technical details that specialists only have in mind, evaluation of results of treatment and of the whole campaign cannot be made without doctors trained in the clinical observation of leprosy patients. The coordination of all efforts made in the country nceds someone to be responsible at the national level.

The specific task of an integrated programme is to obtain a sufficient standard of work for a true control and avoid botched work. For a good quality of work at all levels of the system some specialists are necessary. They control diagnosis, treatment and results of treatment. They give technical directions for the treatment of complications and bring their ability to the execution of leprosy control.

As well as technicians they are also trainers for work in leprosy control which duty is often considered as an unpleasant one and for which there is very little enthusiasm. Their attitude is of greatest importance in the running of control operations.

In Indonesia these specialists have been posted at three key-positions: the Headquarters of the National Leprosy Control Programme at Djakarta (Leprosy Institute), the Direction of Public Health in each province and the Public Health service of each 'regency' or region of approximately 400,ooo people.

At Headquarters there is a highly qualified leprologist having, in addition, experience of field operations, of planning, of budgetary questions and of personnel management. His main task is to plan and to co-ordinate the whole programme, taking in account the results obtained during operations. 
At the provincial level there is a provincial leprologist, a medical doctor in charge of the execution of the programme given by the Headquarters so as to fit in with the other medical activities of the province, in coordination with other mass campaigns, and by using to the full all medical facilities of the province. He is also the main consultant of the province for leprosy questions.

At the level of a 'regency' or region of approximately 400,000 people, there is a specialized leprosy nurse, who is in charge of the primary control of patients suspected of leprosy, of ascertaining the diagnosis when possible, of fixing the treatment of each individual, of the supervision of patients under treatment, evaluation of their results, proposal for arrests or discharges, and of the stimulation of all operations of leprosy control under the guidance of the Public Health Officer of the 'regency' or region of approximately 400,000 people in co-operation with other nurses in the arca. He is the main sinew of the wholc programme.

For all technical matters these specialists are in direct correspondence, but administrative matters should follow the normal channels.

\section{OPERATIVE FUSION OF THE SPECIALIZED INSTITUTIONS}

WITH THE PUBLIC HEALTH SERVICES

The difficulty of this process is the driving intojuxtaposition of a specialized service on the one hand and a public health service on the other hand. Therefore it was necessary to work for an organic fusion between the two parts, able to suppress discords and disruption. The best way scems to leave the greatest initiative possible to the Provincial Public Health Services in the practical organization of the execution of the programme prepared by the National Centre and to limit the role of this Centre to technical directions, co-ordination and, above all, to effect a complete co-operation between persons working at the level of the province, the 'regency' or region of approximately 400,00o people, and the subdistrict.

Each part of the programme, and every step taken is the result of the co-operation of the Provincial Director of Public Health and the Provincial Leprologist and their whole staff. Each problem is discussed and the decision taken is probably unanimous. The application of personnel is decided in common. It is a team-work at the level of the province and the 'regency' or region of approximately 400,000 people.

Apart from the planning of the campaign, room for co-operation exists for the stages of case-finding, treatment and evaluation. For these stages there are both public health personnel and leprosy personnel.

For case-finding a special agreement has been made with the yaws campaign. The training of the djurupatek (yaws worker), done by the leprologist, enables him to recognize leprosy lesions. He is not requested to make the diagnosis. $\mathrm{He}$ is in constant relations with the leprosy nurse who re-examines all listed people, makes the diagnosis and registers patients.

Likewise in the treatment of patients the leprosy nurse co-operates with 
the general nurses in charge of subdistrict polyclinics. He gives them the names of patients to be treated and the age to be given. The exccution is committed to non-specialized personnel under the responsibility of specialized personncl.

Evaluation of results is again a matter of co-operation between general nurses and leprosy nurses, the former reporting to the latter all side effects of the treatment, complications and improvements, the leprosy nurse examining all leprosy patients twice a year at least for the control of their evolution. All important decisions must be submitted to the Public Health Officer of the regency by the leprosy nurse.

As well, all reports made for case-finding and treatment operations are checked by the leprosy nurse and submitted to the 'regency' Public Health Officer who, by this method, is informed on health problems of his 'regency'. So he can co-operate with a thorough knowledge of the matter in planning of leprosy control and in directing his personnel.

'The same methods are used in the work at the level of the province. One should stress again upon the importance of the joining at the 'regency' level where the leprosy nurses are the true sinews of the programme.

\section{CONCLUSIONS}

An attempt of integration at the onset of leprosy control mass campaign has been tried in Indonesia because it fitted with the circumstances of the country: low leprosy endemicity, economic difficulties, scarcity of qualified personnel, etc., but also because this method has many advantages in the organization of a large programme of leprosy control; better use of the cxisting personnel, institutions and equipment, fight against prejudices attached to leprosy in the public, faster expansion of the programme, etc.

Integration is effective at the levels of province, 'regency' region of approximately 400,000 people and subdistrict, it is to say all parts of execution. A specialized Institute and personnel are necessary. Specialized personncl is posted at key-levels for a correct execution of the programme. Their role is this of technicians co-operating closely with existing Public Health services. 